\title{
Proportion of Sexual Dysfunction among Drug Free Patients Suffering from Anxiety Disorders
}

\author{
Rakesh Gandhi' ${ }^{1}$, Mahesh Suthar ${ }^{2}$, Rajkumar $^{3}$, Prashant Mangla ${ }^{4}$
}

\begin{abstract}
${ }^{1}$ Associate Professor, Department of Psychiatry, Medical College and SSG Hospital, Baroda, Gujarat, India. ${ }^{2}$ Assistant Professor, Department of Psychiatry, Medical College and SSG Hospital, Baroda, Gujarat, India. ${ }^{3}$ Resident, Department of Psychiatry, Medical College and SSG Hospital, Baroda, Gujarat, India. ${ }^{4}$ Resident, Department of Psychiatry, Medical

College and SSG Hospital, Baroda, Gujarat, India.
\end{abstract}

\section{ABSTRACT}

\section{BACKGROUND}

Normal sexual behaviour is influenced by a number of factors, including mental illness and psychotropic drugs which are used for the management of mental illness. Anxiety is one of the most important mental illnesses which affects sexual functioning. The aim of this study was to compare sexual dysfunction in drug free patients suffering from anxiety disorders with normal healthy controls.

\section{METHODS}

This was a case control study conducted on subjects coming to Psychiatry OPD in S.S.G. Hospital, Vadodara. Study tools used were DSM-5 Diagnostic Criteria for anxiety disorders, Hamilton Anxiety Rating Scale and Arizona Sexual Experiencing Scale.

\section{RESULTS}

Sexual dysfunction was reported by $65 \%$ of patients with anxiety disorders, with most common complain of low desire in both males and females. With increasing severity of anxiety disorder, the rate of sexual dysfunction also increased.

\section{CONCLUSIONS}

Sexual dysfunction occurs in significant amount in patients with anxiety disorders which must be explored in detail during clinical interview and should be advised proper management for better outcome of patients.

\section{KEY WORDS}

Sexuality, Drug Free, Impotence, Anxiety
Corresponding Author:

Dr. Mahesh Suthar,

\#201, Vivanta Classic,

Behind Soham Bunglow,

Vasna Road, Vododara-390016,

Gujarat, India.

E-mail: drmaheshsuthar@gmail.com

DOI: $10.14260 /$ jemds/2019/574

Financial or Other Competing Interests: None.

How to Cite This Article:

Gandhi R, Suthar M, Rajkumar, et al. Proportion of sexual dysfunction among drug free patients suffering from anxiety disorders. J. Evolution Med. Dent. Sci. 2019;8(33):2639-2643, $10.14260 /$ jemds/2019/574

Submission 10-12-2018,

Peer Review 16-02-2019,

Acceptance 22-02-2019,

Published 26-08-2019. 


\section{BACKGROUND}

Sexual function is a complex area that includes emotions, perception, self-esteem, complex behaviour and the ability to initiate and complete sexual activity. Important aspects are the maintenance of sexual interest, the ability to achieve arousal, the ability to achieve orgasm and self-esteem. Many factors influence the reported incidence of sexual dysfunction. These include the method of enquiry,(1) the expectations people have of their sexual performance and their willingness to discuss problems varies widely between different cultures,(2) many terms used to define sexual dysfunction are subjective and dependent on ideas of what is normal; and finally, temporal trends can occur as increased awareness of sexual matters and availability of medical treatments increase the numbers who perceive themselves as suffering from sexual dysfunction.(3)

Sexual dysfunctions are highly prevalent, affecting about $43 \%$ of women and $31 \%$ of men.(4) Hypoactive sexual desire disorder has been reported in approximately $30 \%$ of women and $15 \%$ of men in population- based studies, and is associated with a wide variety of medical and psychological causes. Sexual arousal disorders, including erectile dysfunction in men and female sexual arousal disorder in women, are found in $10 \%$ to $20 \%$ of men and women, and is strongly age-related in men. Orgasmic disorder is relatively common in women, affecting about $10 \%$ to $15 \%$ in community-based studies. In contrast, premature ejaculation is the most common sexual complaint of men, with a reporting rate of approximately $30 \%$ in most studies. Finally, sexual pain disorders have been reported in $10 \%$ to $15 \%$ of women and less than $5 \%$ of men. In addition to their widespread prevalence, sexual dysfunctions have been found to impact significantly on interpersonal functioning and overall quality of life in both men and women.(5) Prevalence of sexual dysfunction in a study was found to be $75 \%$ in patients with panic disorder.6) This was confirmed in another retrospective study which evaluated the sexual function and the sexual history of patients with panic disorder and social phobia. It was also found that sexual aversion disorder is the most common sexual dysfunction in patients with panic disorder, and that its prevalence in this population is greater than in the general population. Furthermore, they also found that sexual aversion was secondary to panic disorder. These results were found in both men and women and suggest that sexual aversion may be part of the agoraphobic spectrum.(7)

Studies on sexuality in patients with social phobia show a co-morbidity of about $30 \%$. Arousal disorders and orgasmejaculation disorders are most common in males with social phobia, ${ }^{(8)}$ while some studies have found a high prevalence of premature ejaculation (47\%),(7) whereas others found a link with retarded ejaculation (33\%).(9) Pleasure and sexual satisfaction are impaired in persons with social phobia.(7-10) Women with social phobia are more likely to have concomitant desire disorders (46\%), pain during sex (42\%), and less frequency of sexual thoughts and sexual intercourse.(8) Sexual dysfunctions have a prevalence of 39\% in females with obsessive compulsive disorder (OCD).(11) Patients may report sexual disgust, the absence of sexual desire, very low sexual arousal, anorgasmia and high avoidance of sexual intercourse.(12,13) They show severe impairment in both interpersonal and sexual relationships ${ }^{(14)}$ and they tend to perceive themselves as less sensual in comparison to patients with other anxiety disorders.(12) The results are a poor level of sexual pleasure(14) and a strong dissatisfaction with their sexuality (73\%).(11)

Post-traumatic stress disorder (PTSD) affects emotional, social, professional, and sexual life.(15,16) It is still unclear whether such populations have normal levels of sexual desire.(17,18) Certainly, these patients have erectile dysfunction (Prevalence of about $69 \%$ in combat veterans with PTSD) and problems with orgasm, and thus report a poor level of sexual satisfaction.(17-19)

Impairment in sexual function is frequent and underestimated in patients with mental disorders, particularly in those with anxiety disorders. They are usually prescribed antidepressant/antianxiety medications, which are known to cause substantial sexual dysfunction. Simply exemplifying the dysfunction caused by medications is imperfect unless the dysfunction caused by the disease is clearly demarcated. Although it is important to study and document the effects of antidepressant medication on sexual functioning, it is equally important to establish a baseline level of sexual interest and sexual function in such patients prior to the initiation of treatment with medication.

We wanted to compare sexual dysfunction in drug free patients suffering from anxiety disorders with normal healthy controls.

\section{METHODS}

This was a time bound case control study in which subjects who fulfilled the inclusion criteria were enrolled consecutively for a period of six months. Both cases and controls were taken from Psychiatry outpatient department at S.S.G. Hospital, Vadodara. Cases were new patients coming to Psychiatry outpatient department for consultation and diagnosed as having anxiety disorders and who were not on any kind of medication. Controls were taken from healthy relatives of patients. They were matched for age, sex, and marital status. Subjects were enrolled after getting written approval from the Institutional Ethics Committee for Human Research.

\section{Inclusion Criteria for Cases}

1. Patients coming to Psychiatry outpatient department for consultation and diagnosed as anxiety disorders according to DSM-5.

2. Aged $\geq 18$ years.

3. Gave written informed consent for study.

4. Did not have history of or concurrent active major medical illness.

5. Were antianxiety or antidepressant free for a minimum of 2 weeks prior to treatment ( 5 weeks in the case of Fluoxetine).

\section{Exclusion Criteria for Cases}

1. Patients with exposure to any psychotropic medication in the previous month.

2. Patients suffering from illness such as diabetes, severe hepatic disease, hypertension or any other disease that may cause sexual dysfunction.

3. Patients on any drugs that affect sexual function. 
4. History of other psychiatric illness.

5. Patient who were pregnant or within 2 months of postpartum period.

6. Patients having psychotic symptoms.

\section{Inclusion Criteria for Controls}

1. Healthy relatives of patients coming to Psychiatry outpatient department.

2. Aged $\geq 18$ years.

3. Gave written informed consent for study.

4. Did not have history of or concurrent active major medical illness or psychiatric illness.

\section{Exclusion Criteria for Controls}

1. Those suffering from illness such as diabetes, severe hepatic disease, hypertension or any other disease that may cause sexual dysfunction.

2. Those suffering from or having history of psychiatric illness.

3. Those who were pregnant or within 2 months of postpartum period.

\section{Study Tools}

1. DSM-5 Diagnostic Criteria(20): For diagnosis of anxiety disorders.

2. Hamilton Anxiety Rating Scale (HAM-A)(21): For assessment of the severity of anxiety disorders.

3. Arizona Sexual Experiencing Scale (ASEX)(22): For assessment of severity of sexual dysfunction.

\section{Statistical Analysis}

Data collected was entered in Excel sheet master chart and was analyzed using MedCalc - version 11.1.0.0. Appropriate statistical tests i.e., frequency, percentage, median, chi-square and Mann-Whitney U tests were performed.

\section{RESULTS}

\section{Demographic Characteristics}

Age wise distribution: $58.3 \%$ patients from study group were of 18-38 age group and $60 \%$ of control group were 18-38 years old. Median age of patients with anxiety disorders was 35 years and median age of control group was 27 years. In patients with anxiety disorders $53.3 \%$ were male and $46.7 \%$ were female. Similarly, in control group $55.6 \%$ were male and $44.4 \%$ were female. In the study group, $6.7 \%$ of the subjects were illiterate, $68.3 \%$ were educated up to secondary level, $18.3 \%$ were educated up to higher secondary level and, $6.7 \%$ were graduates; whereas in the control group 3.3\% of the subjects were illiterate, $68.9 \%$ were educated up to secondary level, $22.2 \%$ were educated up to higher secondary level and $5.6 \%$ were graduates. In the study group, $63.3 \%$ of the subjects were married and $33.3 \%$ of were unmarried, divorced/separated and widow; whereas in the control group $67.8 \%$ subjects were married and $30.5 \%$ were unmarried, divorced/separated and widow. In the study group $60 \%$ were urban and $40 \%$ were from rural area and in the control group $59.4 \%$ were from urban and $40.6 \%$ were from rural area.

\begin{tabular}{|c|c|c|}
\hline Demographic Variable & $\begin{array}{l}\text { No. of Patients with } \\
\text { Anxiety Disorders } \\
(\mathrm{N}=180), \mathrm{n}(\%)\end{array}$ & $\begin{array}{c}\text { No. of Control } \\
\text { Subjects }(\mathrm{N}=180), \\
n(\%)\end{array}$ \\
\hline \multicolumn{3}{|l|}{ Age Groups (in Years) } \\
\hline $18-38$ & $105(58.3)$ & $108(60)$ \\
\hline $39-59$ & $48(26.7)$ & $50(27.7)$ \\
\hline$\geq 60$ & $27(15)$ & $22(12.2)$ \\
\hline Age (Median) & 35 & 27 \\
\hline \multicolumn{3}{|l|}{ Gender } \\
\hline Male & $96(53.3)$ & $100(55.6)$ \\
\hline Female & $84(46.7)$ & $80(44.4)$ \\
\hline \multicolumn{3}{|l|}{ Level of Education } \\
\hline Illiterate & $12(6.7)$ & $6(3.3)$ \\
\hline Secondary & $123(68.3)$ & $124(68.9)$ \\
\hline Higher Secondary & $33(18.3)$ & $40(22.2)$ \\
\hline Graduation & $12(6.7)$ & $10(5.6)$ \\
\hline \multicolumn{3}{|l|}{ Marital Status } \\
\hline Unmarried & $45(25)$ & $44(24.4)$ \\
\hline Married & $114(63.3)$ & $122(67.8)$ \\
\hline Divorced/Separated & $15(8.3)$ & $11(6.1)$ \\
\hline Widow & $6(3.3)$ & $3(1.7)$ \\
\hline \multicolumn{3}{|l|}{ Area } \\
\hline Urban & $108(60)$ & 107(59.4) \\
\hline Rural & $72(40)$ & $73(40.6)$ \\
\hline
\end{tabular}

\begin{tabular}{|c|c|c|c|}
\hline & $\begin{array}{c}\text { Patients with } \\
\text { Anxiety Disorders } \\
(\mathbf{N = 1 8 0 )}, \mathbf{n}(\%)\end{array}$ & $\begin{array}{c}\text { Control } \\
\mathbf{N = 1 8 0} \mathbf{~ n} \\
(\%)\end{array}$ & $\begin{array}{c}\mathbf{p} \\
\text { Value }\end{array}$ \\
\hline Overall sexual dysfunction (ASEX item $\geq 18)$ & $117(65)$ & $35(19.4)$ & 0.0001 \\
\hline Sexual dysfunction in males (ASEX item $\geq 18)$ & $51(53.1)$ & $16(16)$ & 0.0001 \\
\hline Sexual dysfunction in females (ASEX item $\geq 18)$ & $66(78.5)$ & $19(23.7)$ & 0.0001 \\
\hline \multicolumn{2}{|c|}{$\begin{array}{c}\text { Table 2. Comparison of Sexual Dysfunction between } \\
\text { Controls and Patients with Anxiety Disorders }\end{array}$} \\
\hline
\end{tabular}

\begin{tabular}{|c|c|c|c|c|}
\hline \multirow{2}{*}{ ASEX Item } & \multicolumn{3}{|c|}{ Anxiety disorder(N=180) } & \multirow{2}{p}{} \\
\cline { 2 - 5 } & $\begin{array}{c}\text { Mild } \\
\mathbf{n}(\%)\end{array}$ & $\begin{array}{c}\text { Moderate } \\
\mathbf{n}(\%)\end{array}$ & $\begin{array}{c}\text { Severe } \\
\mathbf{n}(\%)\end{array}$ & Value \\
\hline All Subjects & 87 & 84 & 9 & \\
\hline Sexual dysfunction (Total score $\geq 18)$ & $36(41.3)$ & $72(85.7)$ & $9(100)$ & 0.0001 \\
\hline Male Subjects & 60 & 36 & 00 & \\
\hline Sexual dysfunction (Total score $\geq 18)$ & $24(40)$ & $27(75)$ & 00 & 0.0018 \\
\hline Female Subjects & 27 & 48 & 9 & \\
\hline Sexual dysfunction(Total score $\geq 18)$ & $12(44.4)$ & $45(93.7)$ & $9(100)$ & 0.0001 \\
\hline Table 3. Comparison of Sexual Dysfunction based on \\
Severity of Anxiety Disorder \\
\hline
\end{tabular}

\begin{tabular}{|c|c|c|c|c|}
\hline $\begin{array}{c}\text { Demographic } \\
\text { Variable }\end{array}$ & $\begin{array}{c}\text { Patients with } \\
\text { Anxiety } \\
\text { Disorders } \\
\text { (N=180) }\end{array}$ & $\begin{array}{c}\text { Sexual } \\
\text { Dysfunction } \\
\mathbf{n}(\%)\end{array}$ & $\begin{array}{c}\text { Chi-Square } \\
\text { Value }\end{array}$ & p Value \\
\hline Area & 72 & $45(62.5)$ & 0.172 & 0.6784 \\
$\begin{array}{c}\text { Rural } \\
\text { Urban }\end{array}$ & 108 & $72(66.6)$ & & \\
\hline $\begin{array}{c}\text { Marital Status } \\
\text { Married }\end{array}$ & 114 & $81(71.1)$ & & \\
$\begin{array}{c}\text { Unmarried/widow/ } \\
\text { Separated }\end{array}$ & 66 & $36(54.5)$ & 4.307 & 0.0379 \\
\hline $\begin{array}{c}\text { Gender } \\
\text { Male }\end{array}$ & 96 & $51(53.1)$ & 11.657 & 0.0006 \\
Female & 84 & $66(78.5)$ & & \\
\hline
\end{tabular}

Table 4. Comparison of Sexual Dysfunction in Patients with Anxiety Disorder Based on Area, Marital Status and Gender

\begin{tabular}{|c|c|c|c|c|}
\hline $\begin{array}{c}\text { Demographic } \\
\text { Variable }\end{array}$ & $\begin{array}{c}\text { Patients } \\
\text { with } \\
\text { Anxiety } \\
\text { Disorders } \\
\text { (N=180) }\end{array}$ & $\begin{array}{c}\text { ASEX total } \\
\text { Score } \\
\text { Median } \\
\text { (Interquartile } \\
\text { Range) }\end{array}$ & $\begin{array}{c}\text { Mann- } \\
\text { Whitney U } \\
\text { (Test } \\
\text { Statistic Z) }\end{array}$ & $\begin{array}{c}\text { p } \\
\text { Value }\end{array}$ \\
\hline $\begin{array}{c}\text { Area } \\
\text { Rural }\end{array}$ & 72 & $\begin{array}{c}21.5(15.5-24.5) \\
21(16-24)\end{array}$ & $3883.5(0.0132)$ & 0.9895 \\
Urban & 108 & & & 0.0030 \\
\hline $\begin{array}{c}\text { Marital status } \\
\text { Married }\end{array}$ & 114 & $22(17-25)$ & $2767.5(2.967)$ & \\
$\begin{array}{c}\text { Unmarried/widow/ } \\
\text { Separated }\end{array}$ & 66 & $19(14-23)$ & & 0.0001 \\
\hline $\begin{array}{c}\text { Gender } \\
\text { Male }\end{array}$ & 96 & $19(14.5-22)$ & $1750.5(6.575)$ & \\
Female & 84 & $24(21-25)$ & & \\
\hline
\end{tabular}

Table 5. Area, Marital Status, and Gender Wise Comparison of Median ASEX Total Score of Patients with Anxiety Disorders 
Among healthy individuals, sexual dysfunction was reported by $19.4 \%$ of subjects $(16 \%$ of males and $23.7 \%$ of females). Most female controls reported difficulty in vaginal lubrication $(23.7 \%)$, followed by low orgasm satisfaction $(15 \%)$, and difficulty in achieving orgasm (13.7\%); and while among male controls maximally reported complaint was difficulty in penile erection (21\%). Difficulty in attaining in sexual excitement was the least prevalent sexual dysfunction among healthy subjects. Among patients with anxiety disorders sexual dysfunction was reported by $65 \%$ of subjects (53.1\% of males and $78.5 \%$ of females). Most common reported sexual dysfunction was low desire (55\%) followed by difficulty in penile erection (43.8\%). Male patients with anxiety disorders had maximal complaints of low desire (43.7\%). Similarly, in female patients with anxiety disorder low desire $(67.8 \%)$ was most frequently reported, followed by around similar frequency in other phases of sexual dysfunction. When compared with controls, sexual dysfunction was more in patients with anxiety disorder in all phases of sexual response cycle. On applying chi-square test, $p$ value $<0.05$ was obtained, which indicates the difference in sexual dysfunction between patients suffering from anxiety disorder and control group, was statistically significant in almost all items of ASEX across both gender except penile erection and orgasm. Findings of the present study were in line with the findings of some of the previously conducted studies.(6-10)

In this study $48.3 \%$ were having mild anxiety disorder, $46.6 \%$ had moderate anxiety disorder and 5\% had severe anxiety disorder. With increasing severity of anxiety disorder, the rate of sexual dysfunction also increased. Patients with moderate to severe anxiety disorder reported more sexual dysfunction, in both genders, compared to patients having mild anxiety disorder. On applying chi square test for trend, the difference in sexual dysfunction was found to be statistically difference in all items of ASEX.

Chi-square test was applied. Chi-square value and $p$ value indicates that the difference of sexual dysfunction based on area was not statistically significant but based on gender and between married \& unmarried/widow/separated were statistically significant.

Mann-Whitney U test was applied. At 95\% confidence level for the median and two tailed probability indicates that the difference of median ASEX total score between rural \& urban population was statistically not significant. On gender wise and between married \& unmarried/widow/separated, median ASEX total score was found to be significant.

\section{DISCUSSION}

In the present study, the prevalence of sexual dysfunction was found to be $65 \%$ which was significantly more than in the healthy control group. Most common complaint was low desire in both males and females and all the phases of sexual cycle were affected. Also, sexual dysfunction increased with increase in severity of anxiety disorders. Significantly higher prevalence of sexual dysfunction and median ASEX scores was found in females and married persons. In the previously conducted studies, the prevalence of sexual dysfunction ranged from $30 \%$ to $75 \%$ and had common complaints of low desire or absence of desire, arousal problems and orgasmic problems. (6-18) Thus, findings in the present study were in line with the previously conducted studies. The advantage of the present study over the above studies is that it is a case control study comparing sexual dysfunction between patients of anxiety disorders and healthy individuals. The limitations of this study include its cross-sectional nature which limits our possibility to explore the cause and effect relationship between anxiety disorders and sexual dysfunction and since data were collected from specific population, the degree to which they represent the general population cannot be commented on.

\section{CONCLUSIONS}

Healthy subjects reported considerable sexual dysfunction despite being physically and psychiatrically well. Anxiety disorders affect all the phases of sexual functioning. Patients with anxiety disorders have more sexual dysfunction than controls in all phases of sexual functioning cycle, across both genders. Patients suffering from moderate to severe anxiety disorder had greater frequency of sexual dysfunction compared to mild anxiety disorder.

\section{ACKNOWLEDGEMENT}

The authors would like to acknowledge the support of Dean, Medical College. Baroda and Superintendent, SSG Hospital Baroda for allowing us to conduct this study.

\section{REFERENCES}

[1] Montejo-gonzàlez AL, Llorca G, Izquierdo JA, et al. SSRIinduced sexual dysfunction: fluoxetine, paroxetine, sertraline and fluvoxamine in a prospective, multicenter, and descriptive clinical study of 344 patients. J Sex Marital Ther 1997;23(3):176-94.

[2] Bhugra D, De Silva P. Sexual dysfunction across cultures. Int Rev Psychiatry 1993;5(2-3):243-52.

[3] Baldwin DS. Depression and sexual dysfunction. Br Med Bull 2001;57(1):81-99.

[4] Laumann EO, Paik A, Rosen RC. Sexual Dysfunction in the United States. JAMA 1999;281(6):537-44.

[5] Rosen RC. Prevalence and risk factors of sexual dysfunction in men and women. Curr Psychiatry Rep 2000;2(3):189-95.

[6] Kaplan HS. Anxiety and sexual dysfunction. J Clin Psychiatry 1988;(Suppl 49):21-5.

[7] Figueira I, Possidente E, Marques C, et al. Sexual dysfunction: a neglected complication of panic disorder and social phobia. Arch Sex Behav 2001;30(4):369-77.

[8] Bodinger L, Hermesh H, Aizenberg D, et al. Sexual function and behavior in social phobia. J Clin Psychiatry 2002;63(10):874-9. 
[9] Tignol J, Martin C, Auriacombe M, et al. Case study-relationship between prevalence of shyness, social phobia and avoidant personality in male sexual disorders. Encephale 2001;27(5):418-22.

[10] Ernst C, Földényi M, Angst J. The Zurich Study: XXI. Sexual dysfunctions and disturbances in young adults. Eur Arch Psychiatry Clin Neurosci 1993;243(3-4):17988.

[11] Freund B, Steketee G. Sexual history, attitudes and functioning of obsessive-compulsive patients. J Sex Marital Ther 1989;15(1):31-41.

[12] Aksaray G, Yelken B, Kaptanoğlu C, et al. Sexuality in women with obsessive compulsive disorder. J Sex Marital Ther 2001;27(3):273-7.

[13] Vulink N, Denys D, Bus L, et al. Sexual pleasure in women with obsessive-compulsive disorder? J Affect Disord 2006;91(1):19-25.

[14] Lensi P, Cassano GB, Correddu G, et al. Obsessivecompulsive disorder. Familial-developmental history, symptomatology, comorbidity and course with special reference to gender-related differences. Br J Psychiatry 1996;169(1):101-7.

[15] Zatzick DF, Marmar CR, Weiss DS, et al. Posttraumatic stress disorder and functioning and quality of life outcomes in a nationally representative sample of male Vietnam Veterans. Am J Psychiatry 1997;154(12):16905 .
[16] Solursh LP, Solursh DS. Male erectile disorders in Vietnam combat veterans with chronic post-traumatic stress disorder. Int J Adolesc Med Health 1994;7(2):11924.

[17] Cosgrove DJ, Gordon Z, Bernie JE, et al. Sexual dysfunction in combat veterans with post-traumatic stress disorder. Urology 2002;60(5):881-4.

[18] Kotler M, Cohen H, Aizenberg D, et al. Sexual dysfunction in male posttraumatic stress disorder patients. Psychother Psychosom 2000;69(6):309-15.

[19] Blumentals WA, Gomez-Caminero A, Brown RR, et al. A case-control study of erectile dysfunction among men diagnosed with panic disorder. Int J Impot Res 2004;16(3):299-302.

[20]American Psychiatric Association. Diagnostic and Statistical Manual of Mental Disorders. $5^{\text {th }}$ edn. Washington, DC: American Psychiatric Association 2013.

[21] Hamilton M. The assessment of anxiety states by rating. Br J Med Psychol 1959;32(1):50-5.

[22] McGahuey CA, Gelenberg AJ, Laukes CA, et al. The Arizona Sexual Experience Scale (ASEX): reliability and validity. J Sex Marital Ther 2000;26(1):25-40. 